\title{
III-Nitride QD Lasers
}

\author{
H. Al-Husseini ${ }^{1}$, Amin H. Al-Khursan ${ }^{*}, 1$ and S. Y. Al-Dabagh ${ }^{2}$ \\ ${ }^{I}$ Physics Department, Science College, Thi-Qar University, Nassiriya, Iraq \\ ${ }^{2}$ Physics Department, Science College for Women, Baghdad University, Baghdad, Iraq
}

\begin{abstract}
III-Nitrides QD lasers are studied in detail. Two types of QD structures are considered, GaN/Al $\mathrm{x}_{\mathrm{X}} \mathrm{Ga}{ }_{1-\mathrm{x}} \mathrm{N} / \mathrm{AlN}$ and $\operatorname{In}_{\mathrm{x}} \mathrm{Ga}_{1-\mathrm{x}} \mathrm{N} / \mathrm{In}_{0.04} \mathrm{Ga}_{0.96} \mathrm{~N} / \mathrm{GaN}$. Effects of: QD size; QD and WL composition; and doping are studied through the calculations of gain, threshold current, and intensity modulation bandwidth. It is shown that GaN QDs are less sensitive to size fluctuations. Bandwidth increases with doping and reducing QD size. The study covers approximately $(300-600 \mathrm{~nm})$ wavelength range.
\end{abstract}

\section{INTRODUCTION}

Semiconductor nitrides are very promising materials for their potential use in optoelectronic devices and hightemperature electronic devices. Until few years ago, the commonly quoted value for the optical bandgap of InN was $1.89 \mathrm{eV}$ [1], but new measurements have shown evidence of a much smaller bandgap between 0.65 and $0.9 \mathrm{eV}[2,3]$. The energy range of III-nitride (III-N) alloys from $6.2 \mathrm{eV}$ (pure AlN) to $0.7 \mathrm{eV}$ (pure $\mathrm{InN}$ ) covers the spectral range from deep ultra violet (UV) to infrared (IR) at room temperature. These materials are thus, suitable for applications in UV detectors, Bragg reflectors, waveguides, and UV and visible light emitting diodes (LEDs). GaN-based LEDs and LDs have been achieved using thin films or QWs [1]. Development Laser diodes (LDs) of LDs with quantum dots (QDs), for example, is expected to result in a lower threshold current [4]. To access the advantages of QDs, the maximum size of QDs must be on the order of a few nanometers as a Prequisite for utilization zero-dimensional confinement. With such small size, the practical applications are thus often associated with a large assembly of QDs rather than a single one. This implies that the size uniformity of the dot assembly is critical. Fluctuations in dot size produce an inhomogeneous broadening in quantized energy levels and may destroy the very properties expected from a single QD. Fabrication of a QD assembly with small and uniform size, high density, well-ordered placement, and defect-free materials today remains a serious challenge in any semiconductor system, especially when using III-N materials. The properties of III-N QDs are closely related to those of bulk materials that have been reviewed in many articles [5]. Although bulk GaN, $\mathrm{AlN}$, and InN can all crystallize in wurtzite, zinc blende, and rock salt structures, in ambient conditions, the thermodynamically stable structure, however, is the wurtzitic phase. III-nitride QDs are commonly the strained systems. The lattice mismatch and its induced strain have a profound effect on the growth, structures, and properties of semiconductor QDs.

*Address correspondence to this author at the Physics Department, Science College, Thi-Qar University, Nasinya, Iraq; E-mail: ameen_2all@yahoo.com
Strain induced self-organization of QDs is the common method to fabricate QDs [6]. A theoretical study of III-N QD lasers with the recent progress in these lasers is very important. This work addresses the properties of III-N lasers. The structures chosen are those specified in experiments. For example we use $\mathrm{InGaN} / \mathrm{In}_{0.04} \mathrm{Ga}_{0.96} \mathrm{~N} / \mathrm{GaN}$ structures since some experiments refer to this structure as one of the most stable III-N structures. Beginning from energy level calculation, characteristics like gain and model gain are simulated, then threshold current is specified via rate equations (REs) represent structure layers: the separate confinement heterostructure $(\mathrm{SCH})$ layer, wetting layer (WL), then ground and excited states (GS and ES) in the QD layer. Small signal analysis is applied to these REs to get intensity modulation response. The study covers a wide range of III-N wavelength spectrum. This is done by changing QD and WL composition. Different QD sizes are studied to see the effect of quantization on the above mentioned characteristics. During this study, a comparison between $\mathrm{GaN}$ and $\mathrm{InGaN}$ QDs is done. Importance is taken for some developments such as p-doping to demonstrate the superior of threshold current, and then modulation response, than the undoped structures.

\section{GAIN OF III-N QDS}

\section{A. Model}

Taking strain into account, a quantum disk model [7] is used to calculate the energy levels. Band lineup alignment is used to calculate the band edge among the QD, WL, and $\mathrm{SCH}$. Two types of structures are studied. The first is GaN/Al $\mathrm{Ga}_{1-\mathrm{x}} \mathrm{N} / \mathrm{AlN}$ while the second is $\mathrm{In}_{\mathrm{x}} \mathrm{Ga}_{1-\mathrm{x}} \mathrm{N} /$ $\mathrm{In}_{0.04} \mathrm{Ga}_{0.96} \mathrm{~N} / \mathrm{GaN}$ for different $\mathrm{x}$-mole fraction values. These structures are specified thereafter in Table 1. The choice of these structures depends on the structures studied experimentally of QWs and QDs [5] and also to scan most of the spectrum gotten from the III-N structures. The size of the quantum disks studies are (the radius $\rho=14 \mathrm{~nm}$ and height $\mathrm{h}=2 \mathrm{~nm}$ ) if not referred to. Other QD sizes are also studied. The thickness of the wetting layer (WL) is $5 \mathrm{~nm}$, and that of the barrier is $33 \mathrm{~nm}$. The structures in Table $\mathbf{1}$ study either of these two interesting features. The first is changing WL (Al) composition and the second is changing the QD (In) composition. Thus we study along these calculations the effects of 
Table 1. The Differential Gain and Transparency Surface Carrier Density of the III-N QDs

\begin{tabular}{|c|c|c|c|c|c|}
\hline QD Structure & $\mathbf{a}\left(\mathbf{c m}^{2}\right)$ & $\mathbf{N}_{\text {tr }}\left(\mathbf{c m}^{-2}\right)$ & QD Structure & $\mathbf{a}\left(\mathbf{c m}^{2}\right)$ & $\mathbf{N}_{\text {tr }}\left(\mathbf{c m}^{-2}\right)$ \\
\hline \hline $\mathrm{GaN}^{2} \mathrm{Al}_{0.15} \mathrm{Ga}_{0.85} \mathrm{~N} / \mathrm{AlN}$ & $3.518 \mathrm{E}-19$ & $2.403 \mathrm{E}+12$ & $\mathrm{In}_{0.13} \mathrm{Ga}_{0.87} \mathrm{~N} / \mathrm{In}_{0.04} \mathrm{Ga}_{0.96} \mathrm{~N} / \mathrm{GaN}$ & $8.9 \mathrm{E}-21$ & $3.546 \mathrm{E}+12$ \\
\hline $\mathrm{GaN} / \mathrm{Al}_{0.2} \mathrm{Ga}_{0.8} \mathrm{~N} / \mathrm{AlN}$ & $1.311 \mathrm{E}-18$ & $4.625 \mathrm{E}+9$ & $\mathrm{In}_{0.16} \mathrm{Ga}_{0.84} \mathrm{~N} / \mathrm{In}_{0.04} \mathrm{Ga}_{0.96} \mathrm{~N} / \mathrm{GaN}$ & $5.96 \mathrm{E}-19$ & $2.428 \mathrm{E}+12$ \\
\hline $\mathrm{GaN} / \mathrm{Al}_{0.25} \mathrm{Ga}_{0.75} \mathrm{~N} / \mathrm{AlN}$ & $3.05 \mathrm{E}-18$ & $1.547 \mathrm{E}+12$ & $\mathrm{In}_{0.25} \mathrm{Ga}_{0.75} \mathrm{~N} / \mathrm{In}_{0.04} \mathrm{Ga}_{0.96} \mathrm{~N} / \mathrm{GaN}$ & $1.92 \mathrm{E}-18$ & $2.702 \mathrm{E}+12$ \\
\hline $\mathrm{GaN} \mathrm{Al}_{0.3} \mathrm{Ga}_{0.7} \mathrm{~N} / \mathrm{AlN}$ & $8.022 \mathrm{E}-18$ & $3.023 \mathrm{E}+12$ & $\mathrm{In}_{0.35} \mathrm{Ga}_{0.65} \mathrm{~N} / \mathrm{In}_{0.04} \mathrm{Ga}_{0.96} \mathrm{~N} / \mathrm{GaN}$ & $3.49 \mathrm{E}-18$ & $2.04 \mathrm{E}+12$ \\
\hline
\end{tabular}
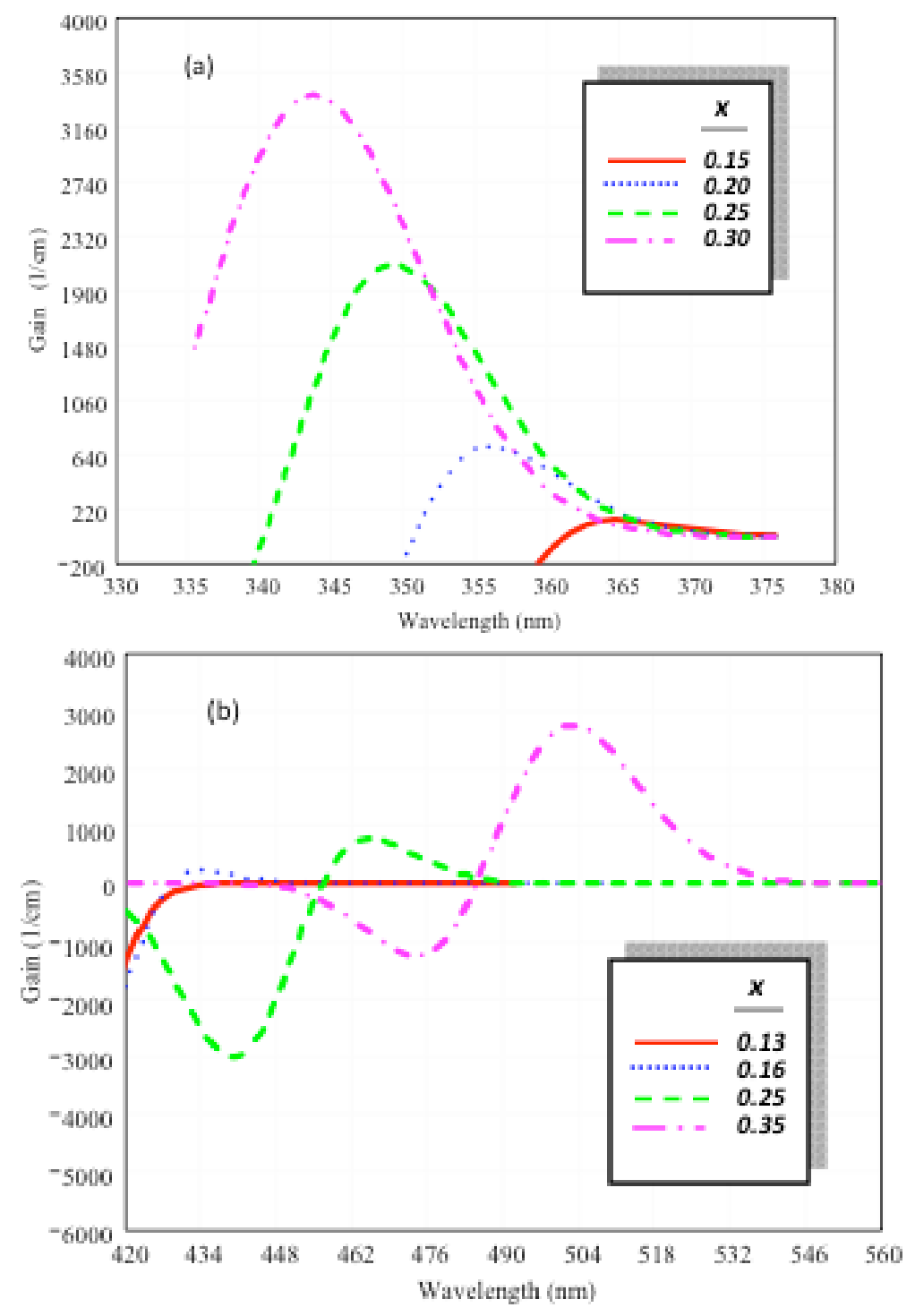

Fig. (1). Gain spectra for: (a) GaN/Al $\mathrm{Ga}_{1-\mathrm{x}} \mathrm{N} / \mathrm{AlN}$ QD structures; (b) $\mathrm{In}_{\mathrm{x}} \mathrm{Ga}_{1-\mathrm{x}} \mathrm{N} / \mathrm{In}_{0 \cdot 04} \mathrm{Ga}_{0}{ }_{96} \mathrm{~N} / \mathrm{GaN}$ QD structures. The structures are with (0 acceptors/QD).

QD sizes, QD composition, WL composition, in addition to p-doping of these structures.

Assuming a homogenous strain [7], the energy levels of the structures are calculated. A behavior similar to that of tight binding calculations [2] is seen where the band structure exactly reflects the behavior expected for the local band structure in the region of the QD where the heavy-hole energy levels are reflected to higher energy. It is evidenced experimentally that $\mathrm{InGaN} / \mathrm{GaN}$ QDs with 3-4nm lateral size have an energy spacing of approximately $100 \mathrm{meV}$ [8]. In our work, $\mathrm{In}_{0.35} \mathrm{Ga}_{0.65} \mathrm{~N} / \mathrm{In}_{0 \cdot 04} \mathrm{Ga}_{0}{ }_{96} \mathrm{~N} / \mathrm{GaN}$ structure is studied at different QD radii (13, 12, 11, 10 and 9nm, respectively). The energy spacing between the $1^{\text {st }}$ two conduction subbands in each size studied is increased with diminishing radius (30, $36,41,48$ and $59 \mathrm{meV}$, respectively). According to this, one can expect the same energy spacing as in [8] at smaller widths. For $\mathrm{GaN} / \mathrm{Al}_{0.25} \mathrm{Ga}_{0.75} \mathrm{~N} / \mathrm{AlN}$ which studied at different $\mathrm{QD}$ radii, a less level spacing is shown. 
Gain is calculated with an inhomogeneous broadening function works as a density of states of self-assembled QDs. A global quasi-Fermi levels including WL is assumed in the QD laser. This model is described well in [7]. The momentum matrix element for wurtzite crystals [1] is used in the gain calculations. Calculations are done at room temperature.

\section{B. Gain Calculations}

Fig. (1a) shows the calculated material gain spectra for $\mathrm{GaN} / \mathrm{Al}_{\mathrm{x}} \mathrm{Ga}_{1-\mathrm{x}} \mathrm{N} / \mathrm{AlN}$ QD structure at surface electron densities per QD layer $\left(n_{2 D}\right) 10^{13} \mathrm{~cm}^{-2}$. An increment in the gain and a blue shift in the wavelength (which is between 330$375 \mathrm{~nm}$ ) are seen with increasing $\mathrm{Al}$ content. Fig. (1b) shows gain curves for $\operatorname{In}_{\mathrm{x}} \mathrm{Ga}_{1-\mathrm{x}} \mathrm{N} / \mathrm{In}_{0 \cdot 04} \mathrm{Ga}_{0 \cdot 96} \mathrm{~N} / \mathrm{GaN}$ QD structure where gain increases with In composition $(\mathrm{x})$ in the dot while emitted wavelength shows a red shift. It covers the range 430-540 nm. Photoluminescence emission from InGaN/GaN QDs measured in [8] covers part of these wavelengths. Comparing curves in Figs. (1a and 1b), shows that GaN QDs have higher gain. The calculated differential gain $(a)$ and surface transparency carrier density $\left(N_{t r}\right)$ values are listed in Table 1.

\section{C. p-Doping Effect}

Fig. (2a) shows the calculated material gain spectra for undoped $\mathrm{GaN} / \mathrm{Al}_{0.3} \mathrm{Ga}_{0.7} \mathrm{~N} / \mathrm{AlN}$ QD structure (dashed curves) at surface electron densities per QD layer $\left(n_{2 \mathrm{D}}=8.3 \times 10^{12}\right.$, $8.6 \times 10^{12}, 9 \times 10^{12}$ and $10^{13} \mathrm{~cm}^{-2}$ ). The peak wavelength $\left(\lambda_{\mathrm{p}}\right)$ is blue shifted with increasing $n_{2 D}$. To get (approximately) the same peak gain value for p-doped structures (solid curves) we use $\left(n_{2 D}=3.7 \times 10^{12}, 5.2 \times 10^{12}, 6.3 \times\right.$ $10^{12}$ and $7.5 \times 10^{12} \mathrm{~cm}^{-2}$ ). The p-doped QD laser requires less surface electron density to achieve the same peak gain than the undoped one due to the hole supply from the p-type doping. Fig. (2b) shows gain curves for doped $\operatorname{In}_{0.25} \mathrm{Ga}_{0.75}$ $\mathrm{N} / \mathrm{In}_{0.04} \mathrm{Ga}_{0.96} \mathrm{~N} / \mathrm{GaN}$ QD structure (solid curves) at surface
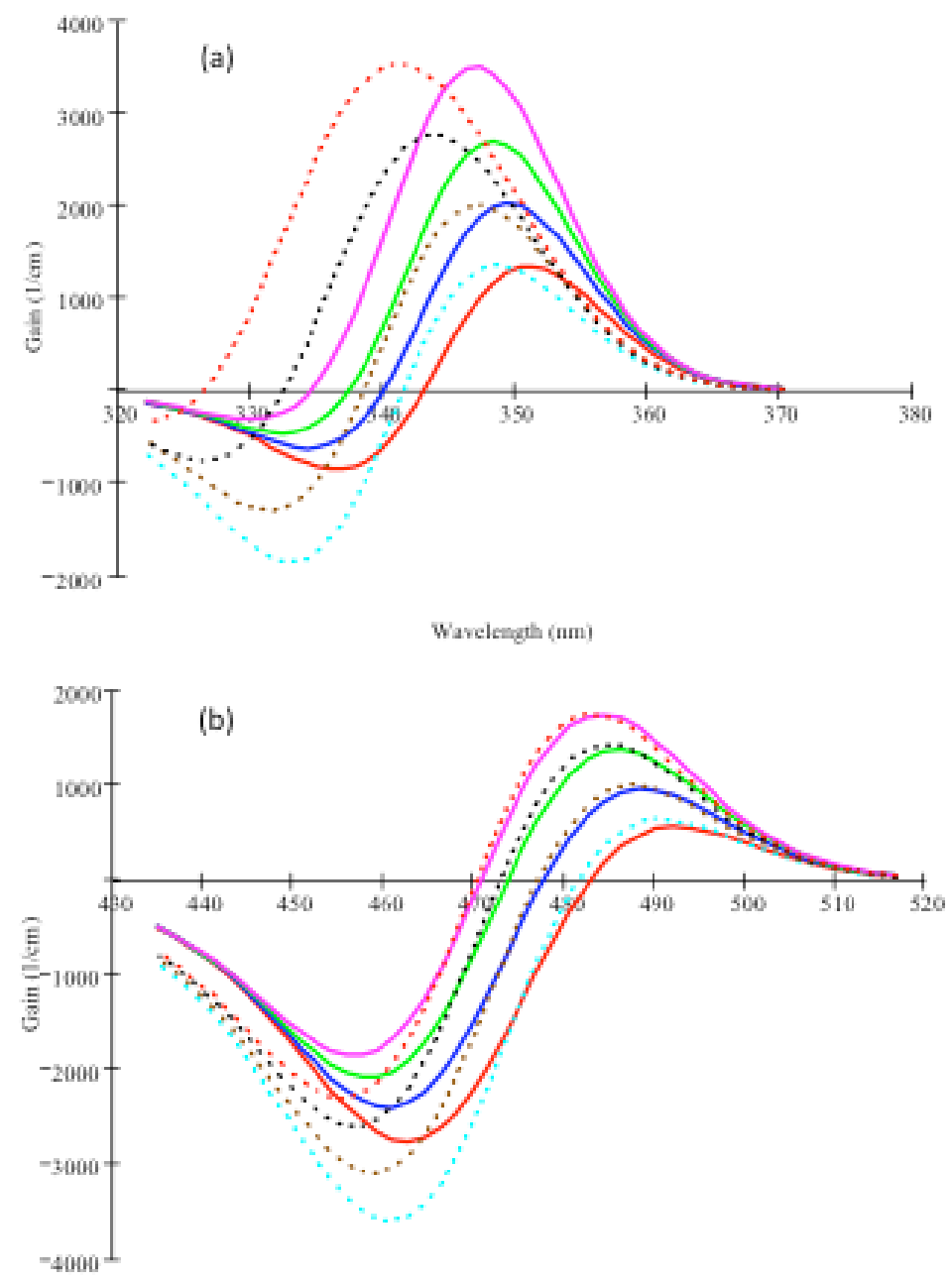

Wavelength (nm)

Fig. (2). (a) Calculated material gain spectra of $\mathrm{GaN} / \mathrm{Al}_{0.3} \mathrm{Ga}_{0.7} \mathrm{~N} / \mathrm{AlN}$ QD laser for undoped structure (dashed curves) with surface electron densities per QD layer $n_{2 D}=8.3 \times 10^{12}, 8.6 \times 10^{12}, 9 \times 10^{12}$ and $10 \times 10^{12} \mathrm{~cm}^{-2}$. Doped structure (solid curves) with surface electron densities per QD layer $n_{2 D}=3.7 \times 10^{12}, 5.2 \times 10^{12}, 6.3 \times 10^{12}$ and $7.5 \times 10^{12} \mathrm{~cm}^{-2}$. (b) An undoped $\operatorname{In}_{0.25} \mathrm{Ga}_{0.75} \mathrm{~N} / \mathrm{In}_{0.04} \mathrm{Ga}_{0.96} \mathrm{~N} / \mathrm{GaN}$ QD laser $(\mathrm{dashed}$ curves) with $n_{2 D}=8 \times 10^{12}, 10.2 \times 10^{12}, 12.9 \times 10^{12}$ and $14.9 \times 10^{12} \mathrm{~cm}^{-2}$ compared with the p-doped ones (solid curves) with $n_{2 D}=4 \times 10^{12}, 6$ $\mathrm{x} 10^{12}, 8 \times 10^{12}$ and $10^{13} \mathrm{~cm}^{-2}$ are used for the p-doped QD laser. 


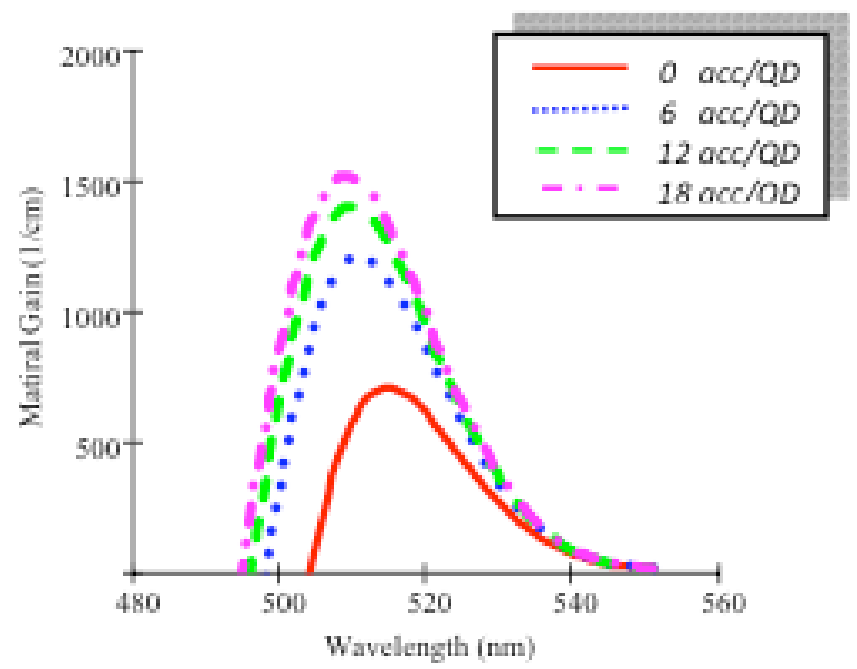

Fig. (3). Comparison of gain spectra for $\operatorname{In}_{0.35} \mathrm{Ga}_{0.65} \mathrm{~N} / \mathrm{In}_{0.04} \mathrm{Ga}_{0.96} \mathrm{~N}$ $/$ GaN QD laser at $n_{2 D}=6 \times 10^{12} \mathrm{~cm}^{-2}$ injection surface carrier density and different acc/QD levels.

electron densities per QD layer $\left(n_{2 D}=4 \times 10^{12}, 6 \times 10^{12}, 8 \times\right.$ $10^{12}$ and $10^{13} \mathrm{~cm}^{-2}$ ) and undoped (dashed curves) ones at $\left(n_{2 D}=8 \times 10^{12}, 10.2 \times 10^{12}, 12.9 \times 10^{12}\right.$ and $14.9 \times 10^{12} \mathrm{~cm}^{-}$ ${ }^{2}$ ). Comparing these curves with those in Fig. (2a) shows that we need more electron density to get the same peak for $\mathrm{In}_{0.25} \mathrm{Ga}_{0.75} \mathrm{~N} / \mathrm{In}_{0.04} \mathrm{Ga}_{0.96} \mathrm{~N} / \mathrm{GaN}$ QD structure while the GaN/AlGaN/AlN p-doped curves shows an obvious red shift not seen in InGaN. III-N QDs needs higher carrier density in comparison with GaAs based QDs [7]; this of course because of a heavier effective masses than the conventional zinc blende crystals. The range of carriers used here $\left(\sim 10^{12}\right.$ $10^{13} \mathrm{~cm}^{-2}$ ) same as that used by [9] to attain gain in $\mathrm{GaN}$ QWs. Let as check the shift in the peak gain wavelength $\left(\lambda_{\mathrm{p}}\right)$ with surface carrier density. In the structures studied in Figs. (2a and $\mathbf{2 b}$ ), for both doped and undoped ones, the increment in $\lambda_{p}$ with surface carrier density is not more than (0.67-5 $\mathrm{nm})$. This means a low dependence of $\lambda_{\mathrm{p}}$ on carrier density. Fig. (3) compares the gain curves at the same surface carrier density $\left(n_{2 D}\right)$ for different doping density (acceptors/QD, acc/QD). At a lower doping density $(0,6)$ gain increases faster, then after (12 acc/QD) the increment becomes small with further doping.

\section{Homogenous and Inhomogeneous Broadening Effect}

QDs known to have a small size, the practical applications are associated with large assembly of QDs. This implies that the size uniformity of the dot assembly is critical. Fluctuations of dot size produce an inhomogeneous broadening in quantized energy levels and may destroy the very properties expected from a single QD. Thus it is important to study the effect of Inhomogeneous broadening of QDs on gain. Fig. (4a) gives the gain variation with the evolution of broadening from homogeneous to inhomogeneous with the assumption of constant temperature. While it maximizes by $\sim 3.5$ times for GaN QDs, it maximizes by $\sim 7$ times for In-
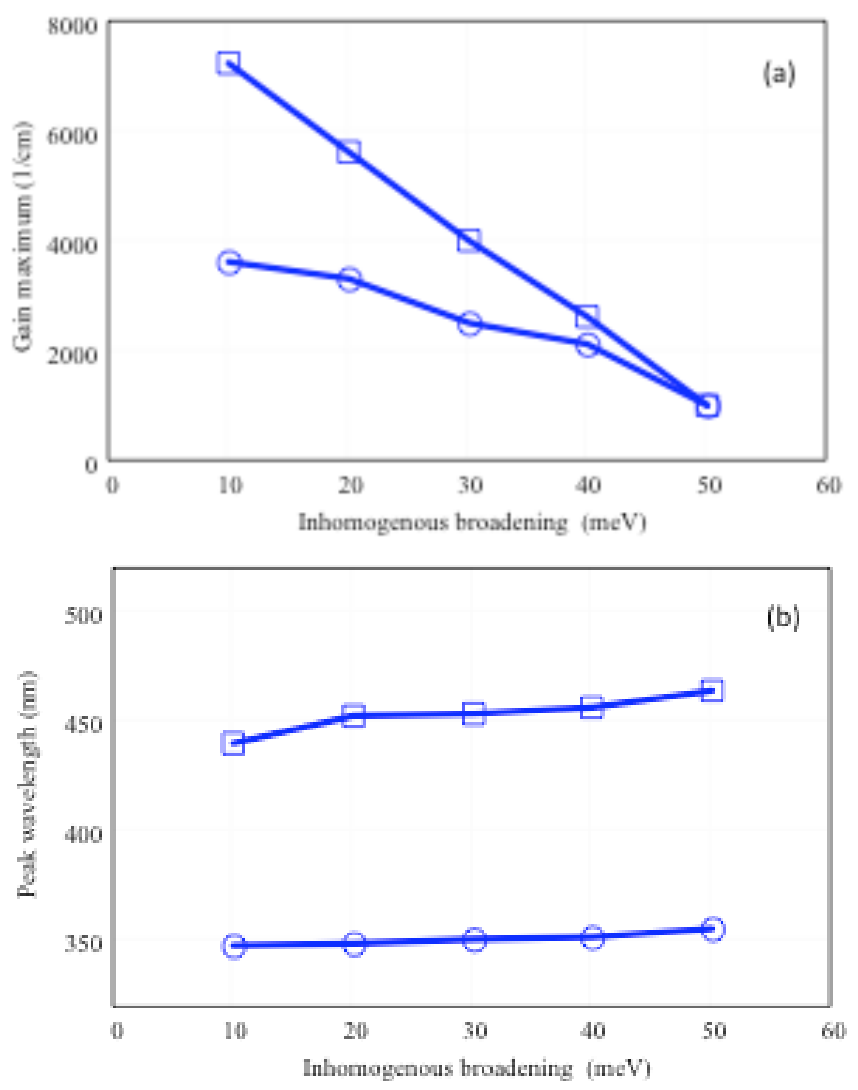

Fig. (4). Inhomogeneous broadening effect for $\mathrm{GaN} / \mathrm{Al}_{0.2} \mathrm{Ga}_{0.8} \mathrm{~N} /$ AlN (circles) and structures $\operatorname{In}_{0.35} \mathrm{Ga}_{0.65} \mathrm{~N} / \mathrm{In}_{0.04} \mathrm{Ga}_{0.96} \mathrm{~N} / \mathrm{GaN}$ (squares) on (a) peak gain, and (b) peak wavelength.

GaN QDs. Fig. (4b) shows $\lambda_{\mathrm{p}}$ variation with broadening. While InGaN changes by $\sim 40 \mathrm{~nm}$, it is $\sim 15 \mathrm{~nm}$ for GaN QDs. From this figure one can see that GaN QDs are less sensitive to size fluctuations than InGaN QDs.

\section{E. Q Disk Size Effects}

To study the quantum size effects on the disk, different shapes are studied by changing their radius and height. Then, gain is calculated. Fig. (5) shows maximum gain $\left(g_{\max }\right)$ and $\lambda_{\mathrm{p}}$ variation with the height of the disk $(h)$ for $\mathrm{GaN} / \mathrm{Al}_{0.25}$ $\mathrm{Ga}_{0.75} \mathrm{~N} / \mathrm{AlN}$ structure at radius $(\rho=14 \mathrm{~nm})$, Fig. (5a), and then with radius at height $(h=2 n m)$, Fig. (5b). It is shown that $g_{\max }$ increases with reducing size ( $\rho$ or $h$ ). Fig. (6) studies size effects on $\operatorname{In}_{0.35} \mathrm{Ga}_{0.65} \mathrm{~N} / \mathrm{In}_{0.04} \mathrm{Ga}_{0.96} \mathrm{~N} / \mathrm{GaN}$. Both Figs. (5 and 6) are done at $\left(n_{2 D}=8 \times 10^{12} \mathrm{~cm}^{-2}\right)$ and $(6 \mathrm{acc} /$ QD). In all of these figures it is shown that $g_{\text {max }}$ increases with reducing size. An interesting phenomenon is the $g_{\max }$ increment in $\mathrm{GaN} / \mathrm{Al}_{0.25} \mathrm{Ga}_{0.75} \mathrm{~N}$ QDs when one scales the disk height from 4 to $3 \mathrm{~nm}$ which appear in Fig. (5a). The gain scales by (18) times increment while all the other cases studied are changes by (1-4) times. This can be explained when one check the number of energy levels. When $h=4 \mathrm{~nm}$ we have (12) levels for CB and (24) levels for VB. When $h=3 \mathrm{~nm}$ we have (12) levels for CB and (16) levels for VB. Thus, the number of VB levels is reduced. However, a nar- 


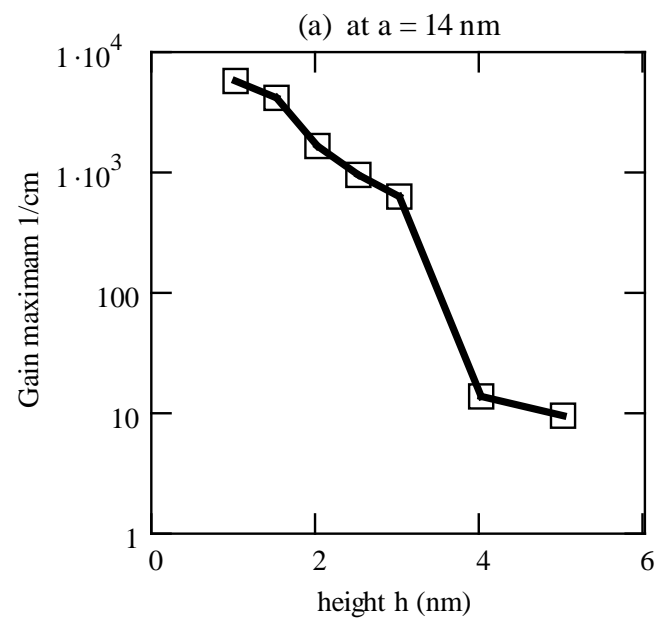

(c) at $\mathrm{h}=2 \mathrm{~nm}$

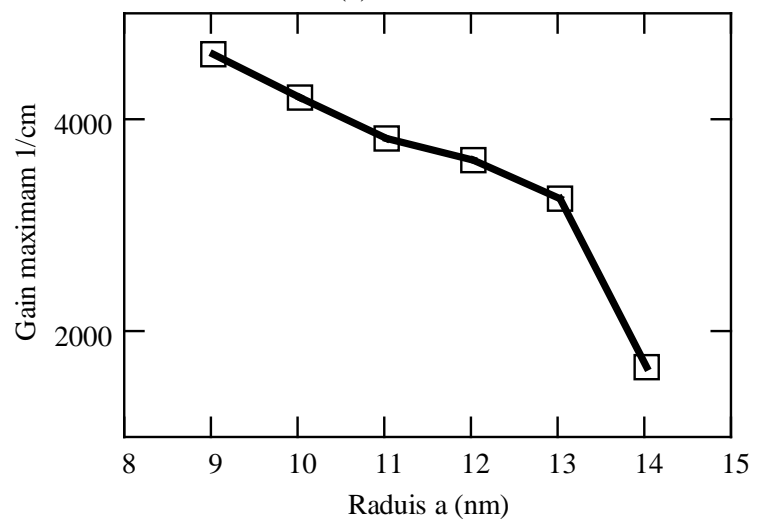

Fig. (5). Gain maximum $g_{\max }$ as a function of disk height (a) and disk radius (b) for $\mathrm{GaN} / \mathrm{Al}_{0.25} \mathrm{Ga}_{0.75} \mathrm{~N} / \mathrm{AlN}$ QD structure. Calculations are done at (6 acc/QD).

row size has a larger separation of subbands, resulting in sharper gain spectra than those of a wider size.

\section{RATE EQUATIONS MODEL}

The occupation probabilities of QD lasers are modeled in the rate equations (REs) by several authors, for example [10] where the QD is assumed to have only two confined energy states, the ground state (GS) and the excited state (ES). GS have a degeneracy equal 2 while ES has degeneracy equal 4 due to the QD symmetry in the growth plane [7]. We add a $\mathrm{RE}$ for the separate confinement heterostructure $(\mathrm{SCH})$ layer to the model, taking into account the Pauli-blocking in the WL, to become have a model includes REs for SCH, WL, GS and ES of QD in addition to the photons Equation. We use this model to calculate threshold current (and then modulation response) for QD structures studied. According to these assumptions in our model, the carriers are injected in the SCH barrier with rate $(I / q)$, relax in the WL state with a rate $\left(1 / \tau_{c, s c h}\right)$ (or escape back in the barrier with a rate $\left.1 / \tau_{e, w l}\right)$. From the WL they can be captured in the dot. Therefore, the WL state acts as a common reservoir from which the carriers are captured in the ES with rate
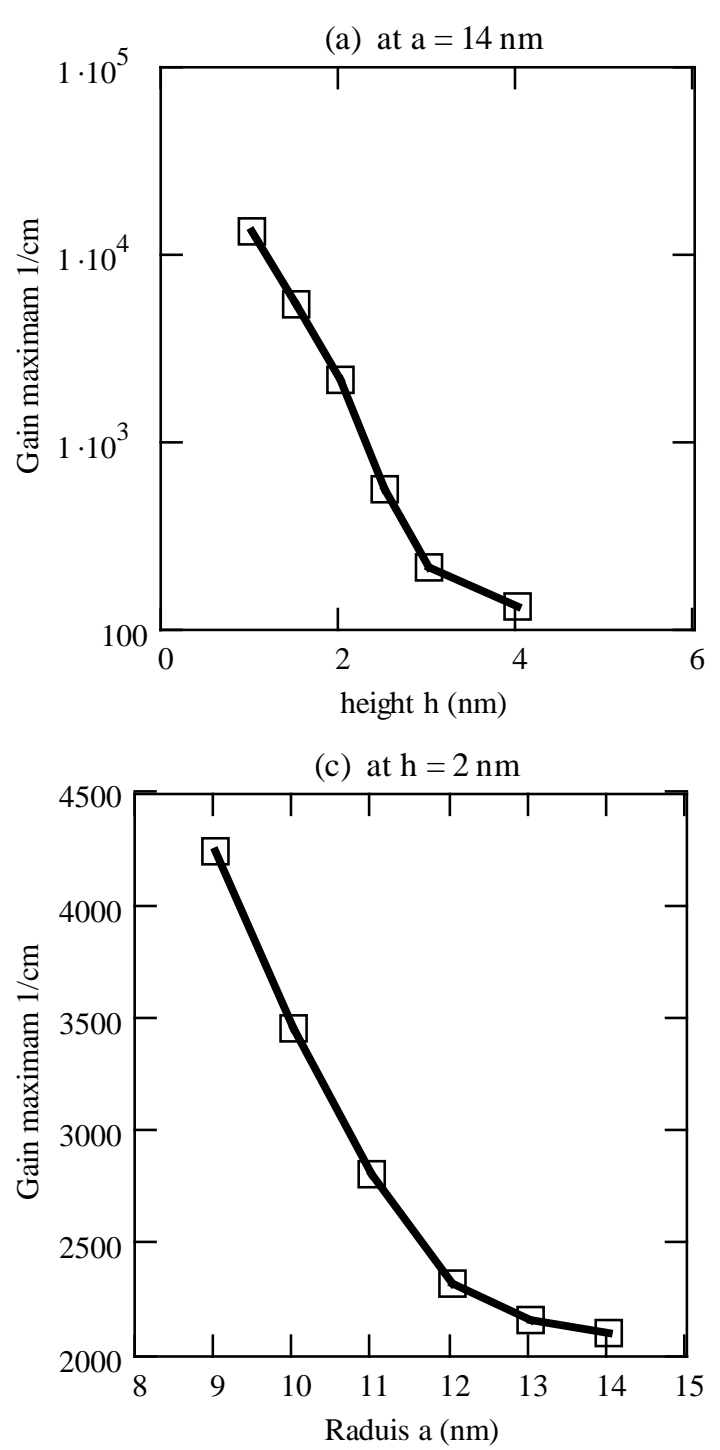

Fig. (6). Gain maximum $g_{\max }$ as a function of disk height (a) and disk radius (b) for $\mathrm{In}_{0.35} \mathrm{Ga}_{0.65} \mathrm{~N} / \mathrm{In}_{0 \cdot 04} \mathrm{Ga}_{0}{ }_{96} \mathrm{~N} / \mathrm{GaN}$ QD structure. Calculations are done at (6 acc/QD).

$\left(1 / \tau_{c, w l}\right)$, and from the ES to the GS with rate $\left(1 / \tau_{c, E S}\right)$. The carriers escape also from the GS back in the ES with rate $\left(1 / \tau_{e, G S}\right)$ or from the ES back in the WL with rate $\left(1 / \tau_{e, E S}\right)$. Carriers can also recombine with radiative (and nonradiative) processes from the $\mathrm{SCH}$, the WL and the various confined states with rates $\left(1 / \tau_{s r}\right),\left(1 / \tau_{w r}\right)$ and $\left(1 / \tau_{r}\right)$, respectively. We assume that the stimulated emission can take place only due to recombination between the electron and hole in the GS [10]. The rate of photons emitted out of the cavity is $\left(S_{p} / \tau_{p}\right)$, with $\tau_{p}$ the corresponding photon lifetime of the mode and $S_{p}$ is the photon occupation probability. The resulting REs system for the carrier occupation probability is as follows: 


$$
\begin{aligned}
& \frac{d f_{s c h}}{d t}=\frac{I}{q}-\frac{f_{s c h}\left(1-f_{w l}\right)}{\tau_{c, s c h}}+\frac{f_{w l}}{\tau_{e, w l}}-\frac{f_{s c h}}{\tau_{s r}} \\
& \frac{d f_{w l}}{d t}=\left(\frac{f_{s c h}}{\tau_{c, s c h}}+\frac{4 f_{E S}}{\tau_{e, E S}}\right)\left(1-f_{w l}\right)-\frac{f_{w l}}{\tau_{e, w l}}-\frac{f_{w l}}{\tau_{c, w l}}\left(1-f_{E S}\right)-\frac{f_{w l}}{\tau_{w r}} \\
& \frac{d f_{E S}}{d t}=\left(\frac{f_{w l}}{4 \tau_{c, w l}}+\frac{f_{G S}}{2 \tau_{e, G S}}\right)\left(1-f_{E S}\right)-\frac{f_{E S}}{\tau_{e, E S}}\left(1-f_{w l}\right)-\frac{f_{E S}}{\tau_{c, E S}}\left(1-f_{G S}\right) \\
& \frac{f_{E S}}{\tau_{r}} \\
& \frac{d f_{G S}}{d t}=\frac{2 f_{E S}}{\tau_{c, E S}}\left(1-f_{G S}\right)-\frac{f_{G S}}{\tau_{e, G S}}\left(1-f_{E S}\right)-\frac{f_{G S}}{\tau_{r}}-v_{g} \Gamma g_{G S} S_{p} \\
& \frac{d S_{p}}{d t}=v_{g} \Gamma g_{G S} S_{p}-\frac{S_{p}}{\tau_{p}}+\beta \frac{2 f_{G S}}{\tau_{r}}
\end{aligned}
$$

The occupation probabilities for the GS and ES are defined as $f_{G S}=n_{G S} / 2 N_{D}$ and $f_{E S}=n_{E S} / 4 N_{D}$, where $n_{G S}\left(n_{E S}\right)$ is the number of electron-hole (e-h) pairs in the $G S(E S), N_{D}$ is the total number of QDs, $g_{G S}$ is the GS gain while the SCH and WL populations and the photon occupation are described by the normalized terms: $f_{s c h}=n_{s c h} / N_{D}, \quad f_{w l}=n_{w l} / N_{D}$, and $S_{p}=n_{p} / N_{D}$, respectively. Note that $n_{P}$ is the photon number. $I$ is the injection current, $q$ is the electron charge, and $\Gamma$ is the confinement factor. In Eq. (5), the last term on the right-hand side $\left(\beta 2 f_{G S} / \tau_{r}\right)$ represents the rate of photons emitted by spontaneous emission coupled into the lasing mode. The size inhomogeneity of the dots is also included through the expression of the capture and escape times; in Eqs. (1-4) these time constants are given by Eq. (6) [11] at the bottom of the page.

$$
\tau_{c, s c h}, \tau_{c, w l} \text {, and } \tau_{c, E S} \text { are the average capture times }
$$

from the SCH to the WL, from the WL to the ES and from the ES to the GS, respectively, with the hypothesis that the final state is empty. The emission times $\tau_{e, G S}$, and $\tau_{e, E S}$ are the escape from the GS back in the ES and the escape from the ES back in the WL. $\tau_{o}^{-1}$ is the relaxation rate when the level state is unoccupied, i.e., $f=0$. As $f$ approaches 1 the relaxation rate decreases, resulting in the occupation of the upper level. Furthermore, at room temperature and before reaching stimulated emission the system must converge to a quasi-thermal equilibrium characterized by a Fermi distribution of the carriers in all the states. To ensure this convergence the carrier escape times are related to the carrier capture times as in Eq. (7) [11], which appears in bottom of this page.

With $S_{1}$ and $S_{2}$ are the degeneracy of the GS and ES levels, $E_{G S}, E_{E S}$ and $E_{w l}$ are the energies of the GS, ES and the first WL level, respectively. In the above expressions $N_{d}$ is the density of QDs per unit area, $N_{w}$ is the number of QD layers and $H_{b}$ is the total thickness of the $\mathrm{SCH}$. $\rho_{w l_{\text {eff }}}\left(\rho_{\text {sch }}\right)$ is the density of states per unit area (volume) in the WL (SCH). They are given by Eq. (8) [11] which appears at the bottom of the page.

$$
\begin{aligned}
& \tau_{c, s c h}^{-1}=\left(1-f_{w l}\right) \tau_{c 0, s c h}^{-1}, \tau_{c, w l}^{-1}=\left(1-f_{E S}\right) \tau_{c 0, w l}^{-1}, \tau_{c, E S}^{-1}=\left(1-f_{G S}\right) \tau_{c 0, E S}^{-1}, \\
& \tau_{e, G S}^{-1}=\left(1-f_{E S}\right) \tau_{e 0, G S}^{-1}, \tau_{e, E S}^{-1}=\left(1-f_{w l}\right) \tau_{e 0, E S}^{-1} \\
& \tau_{e, G S}=\tau_{c, E S} \frac{s_{1}}{s_{2}} e^{\frac{E_{E S}-E_{G S}}{K_{B} T}}, \tau_{e, E S}=\left(\frac{N_{d} s_{1}}{\rho_{w l_{e f f}}}\right) \tau_{c, w l} e^{\frac{E_{w l}-E_{E S}}{K_{B} T}} \\
& \tau_{e, w l}=\left(\frac{\rho_{w l_{e f f}} N_{w}}{\rho_{s c h} H_{b}}\right) \tau_{c, s c h} e^{\frac{\Delta E_{w l, w l}}{K_{B} T}} \\
& \rho_{w l_{e f f}}=\frac{m_{e w l} K_{B} T}{\pi \hbar^{2}}, \quad \rho_{s c h}=2\left(\frac{2 m_{e s c h} \pi K_{B} T}{\hbar^{2}}\right)^{3 / 2}
\end{aligned}
$$



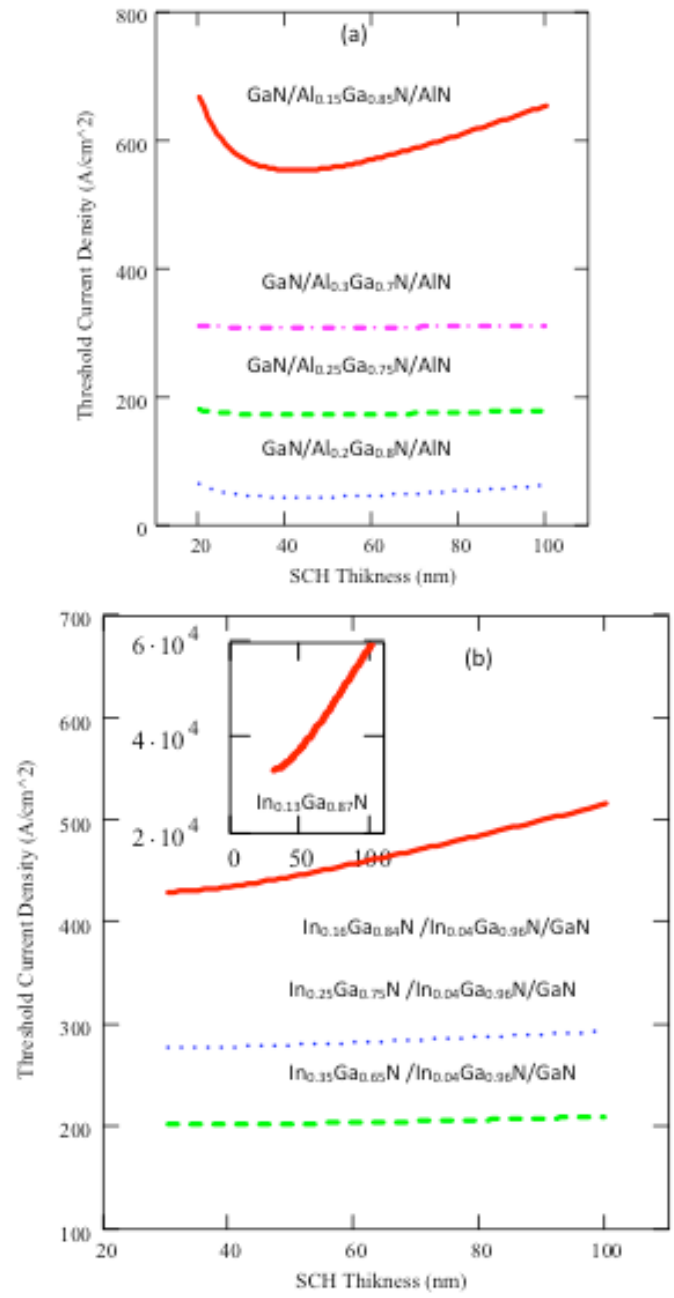

Fig. (7). (a) and (b) The threshold current density $J_{t h}$ as a function of the SCH thickness $L_{s c h}$.

REs (1)-(4) are solved analytically, at steady state by setting all time derivatives to zero, to get analytical expression for the threshold current density. The small-signal solution $[12,13]$ for these REs is done thereafter to get a relation for the intensity modulation response.

\section{THRESHOLD CURRENT}

Table 2 reports the parameters of the QD material and the laser cavity under investigation. The QD material parameters are corresponds to those of an $\mathrm{InGaN} / \mathrm{InGaN} / \mathrm{GaN}$ and
GaN/AlGaN/AlN QD material systems. Dependence of threshold current density $\left(J_{t h}\right)$ on the thickness of $\mathrm{SCH}$ layer $\left(L_{s c h}\right)$ is shown in Fig. (7a and $\left.7 \mathbf{b}\right) . J_{t h}$ is shown to have a minimum at some value of $L_{s c h}$. GaN structures studied in Fig. (7a) depend on changing WL composition. $J_{t h}$ accounts from REs model depends on occupation probabilities of WL and SCH. III-N structures have high threshold current. This high threshold current for N-containing laser is also measured experimentally for InGaAsN QD laser $\left(577 \mathrm{~A} / \mathrm{cm}^{2}\right)$ [14], which is in the same range of our calculations seen in Figs. (7a and 7b). While in Fig. (7b) $J_{t h}$ decrease with increasing in composition, in Fig. (7a) the picture is not in this simplest arrangement. $J_{t h}$ decreases first with Al composition then it increases. Table 1 gives an explanation of this picture where the transparency surface carrier density have the same arrangement appear in Fig. (7a).

\section{A. p-Doping Effect}

Fig. (8a and $\mathbf{8 b}$ ) shows $J_{t h}$ versus $\mathrm{SCH}$ thickness for $\mathrm{GaN} / \mathrm{Al}_{0.15} \mathrm{Ga}_{0.85} \mathrm{~N} / \mathrm{AlN}$ and $\mathrm{In}_{0.16} \mathrm{Ga}_{0.84} \mathrm{~N} / \mathrm{In}_{0.04} \mathrm{Ga}_{0.96} \mathrm{~N} / \mathrm{GaN}$ structures at different doping densities. The interesting feature can be seen is the $J_{t h}$ reduction with doping. The optimum values are stated in Table 3 . It is shown that increasing doping from 0 to 18 acceptors reduces $J_{\text {th }}$ by $\sim 7$ times for $\mathrm{In}_{0.16} \mathrm{Ga}_{0.84} \mathrm{~N}$ and 3 times for $\mathrm{GaN}$ QDs and the minimum $L_{s c h}$ reduces by $4 \mathrm{~nm}$. One must note that we chose these two structures with higher threshold and the GaN structure chosen have threshold higher than that of InGaN chosen as seen in Fig. (7). The modal gain spectra for GaN QDs are shown in Fig. (9a) while $\operatorname{In}_{0.35} \mathrm{Ga}_{0.65} \mathrm{~N}$ spectra are shown in Fig. (9b). Factors are taken from Table 2. The optical confinement factor $(\Gamma)$ is calculated for these structures as $(0.026)$ for $\mathrm{GaN}$ and (0.030) for InGaN QDs. In Fig. (9a) the maximum modal gain of the $\mathrm{GaN} / \mathrm{Al}_{0.3} \mathrm{Ga}_{0.7} \mathrm{~N} / \mathrm{AlN}$ QD laser is $110 \mathrm{~cm}^{-1}\left(11 \mathrm{~cm}^{-1}\right.$ per QD layer) at the wavelength of 349 $n m$. In Fig. (9b) the peak modal gain is $14 \mathrm{~cm}^{-1}$ at the lasing wavelength of $509 \mathrm{~nm}$ for $\mathrm{In}_{0.35} \mathrm{Ga}_{0.65} \mathrm{~N} / \mathrm{In}_{0.04} \mathrm{Ga}_{0.96} \mathrm{~N} / \mathrm{GaN}$ QD laser. These high maximum modal gain values are achievable due to p-type doping with ten layers of QDs. The higher $\Gamma$ value for InGaN contributes in its lower $J_{t h}$ and higher model gain. A modal gain of $20 \mathrm{~cm}^{-1}$ is measured for

Table 2. Parameters of the QD Material and Laser [10]

\begin{tabular}{|c|c|}
\hline QD Material Parameters & Laser Parameters \\
\hline \hline Diffusion in $\mathrm{SCH}, \tau_{\mathrm{c}, \mathrm{sch}}=1 \mathrm{ps}$ & Active region length, $\mathrm{L}=900 \mathrm{~nm}$ \\
\hline SCH recombination, $\tau_{\mathrm{sr}}=4.5 \mathrm{~ns}$ & Active region width, $\mathrm{W}=0.1 \mu \mathrm{m}$ \\
\hline WL recombination, $\tau_{\mathrm{wr}}=3 \mathrm{~ns}$ & Number of QD layers, $\mathrm{N}_{\mathrm{w}}=10$ \\
\hline Capture from WL to $\mathrm{ES}, \tau_{\mathrm{c}, \mathrm{wl}}=1 \mathrm{ps}$ & QD density per unit area, $\mathrm{N}_{\mathrm{d}}=5 \times 10^{12} \mathrm{~cm}^{-2}$ \\
\hline Capture from ES to GS, $\tau_{\mathrm{c}, \mathrm{ES}}=7 \mathrm{ps}$ & Internal loss, $\alpha_{\mathrm{int}}=3 \mathrm{~cm}^{-1}$ \\
\hline ES and GS recombination, $\tau_{\mathrm{r}}=2.8 \mathrm{~ns}$ & Spontaneous emission factor, $\beta=10^{-4}$ \\
\hline Inhomogeneous broadening (Gaussian FWHM) $50 \mathrm{meV}$ & \\
\hline
\end{tabular}



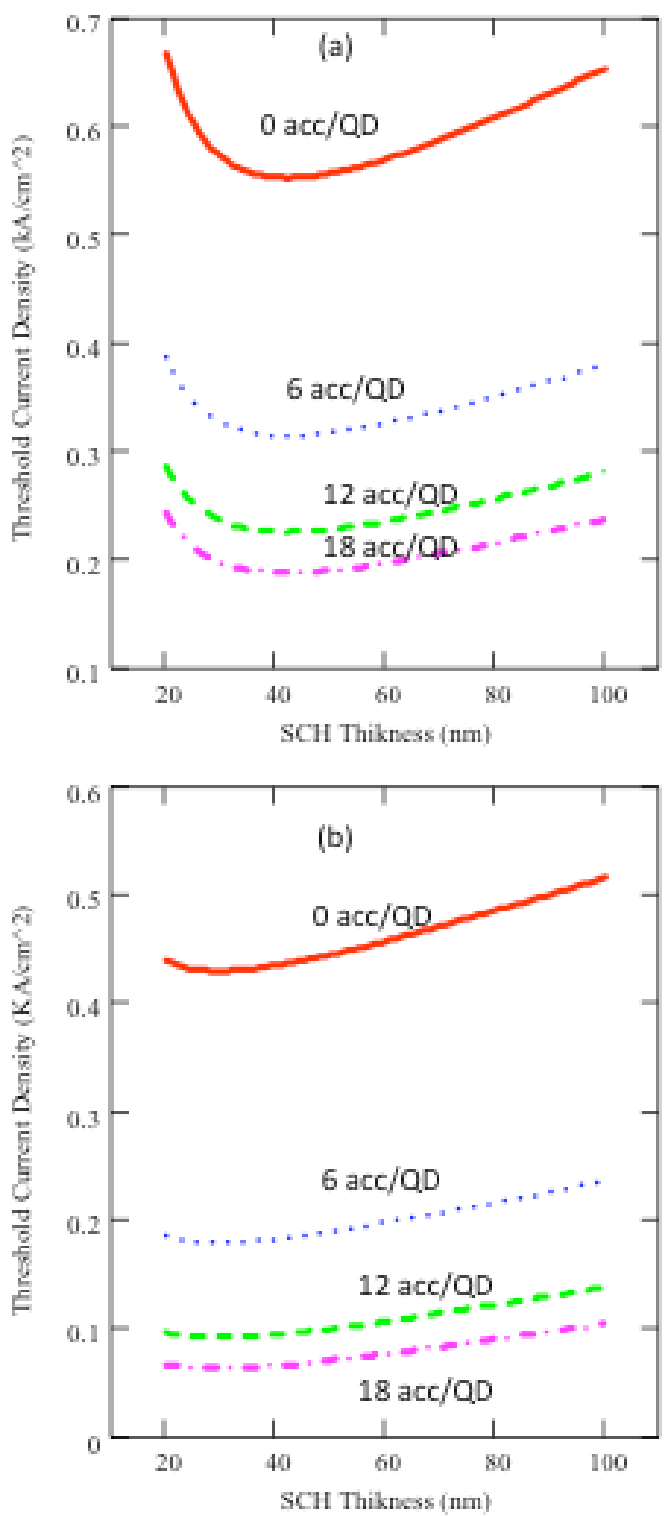

Fig. (8). Threshold current density as function thickness of $\mathrm{SCH}$ for (a) doped $\mathrm{GaN} / \mathrm{Al}_{0.15} \mathrm{Ga}_{0.85} \mathrm{~N} / \mathrm{AlN}$ QD structure (b) doped $\mathrm{In}_{0.16} \mathrm{Ga}_{0.84} \mathrm{~N} / \mathrm{In}_{0.04} \mathrm{Ga}_{0.96} \mathrm{~N} / \mathrm{GaN}$ QD structure.

InAs/InGaAs [7] at $\lambda_{\mathrm{p}}=1288 \mathrm{~nm}$, and calculated to be $28 \mathrm{~cm}^{-1}$ for $\mathrm{InAs} / \mathrm{GaAs}$ at $\lambda_{\mathrm{p}}=0.96 \mathrm{eV}$ [11]. So, compared with these results it is shown to be acceptable as one appreciates $\mathrm{GaN}$ to GaAs materials.
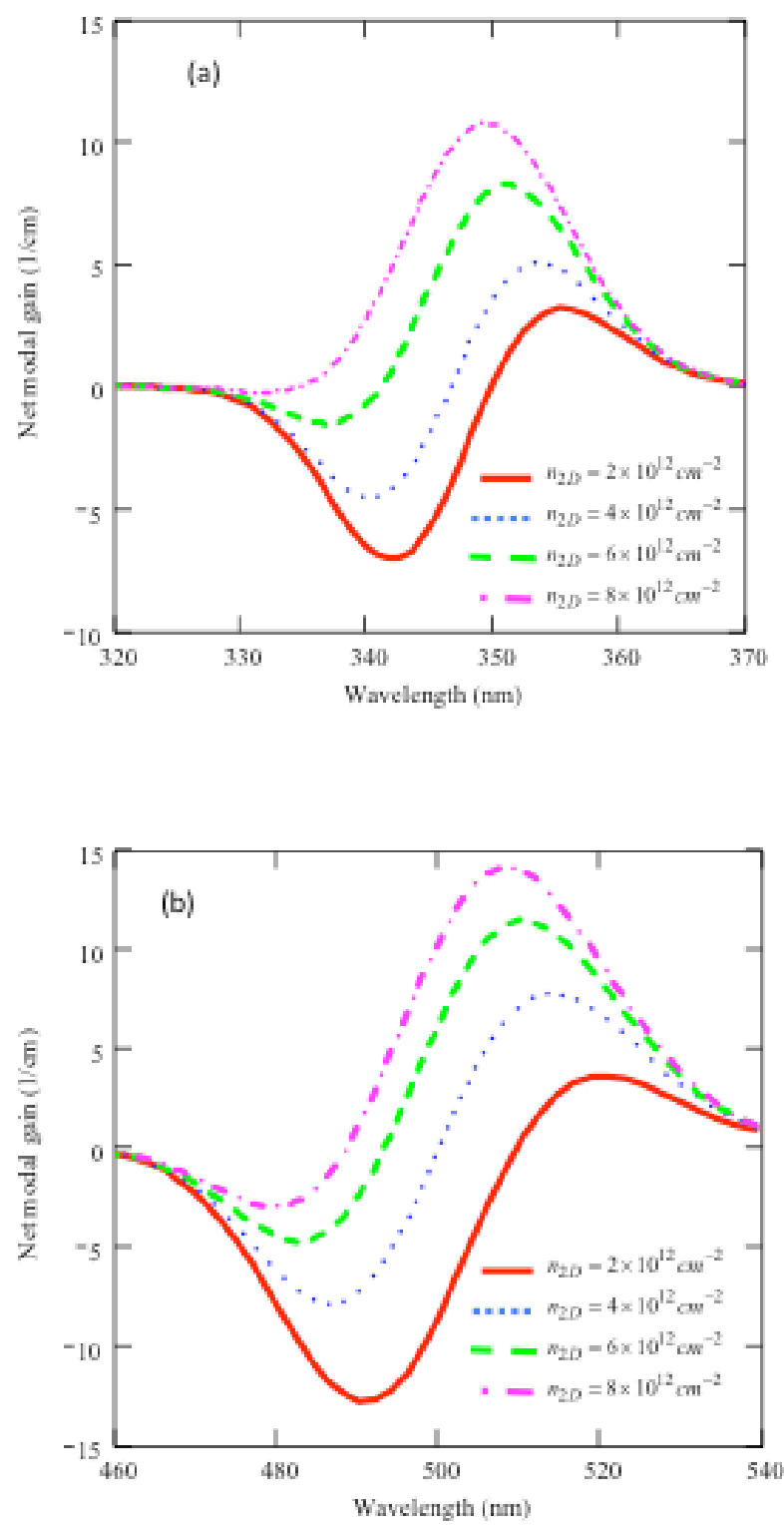

Fig. (9). Calculated net modal gain spectra of a p-doped (a) GaN/Al ${ }_{0.3} \mathrm{Ga}_{0.7} \mathrm{~N} / \mathrm{AlN}$ QD laser (b) $\mathrm{In}_{0.35} \mathrm{Ga}_{0.65} \mathrm{~N} / \mathrm{In}_{0.04} \mathrm{Ga}_{0.96} \mathrm{~N} / \mathrm{GaN}$ QD laser, at various surface electron densities per QD layer.

\section{INTENSITY MODULATION RESPONSE}

Applying small signal response on the REs model, intensity modulation (IM) for III-N QDs is studied. Quantum size

Table 3. Effect of Doping on the Threshold Current Density

\begin{tabular}{|c|c|c|c|c|c|}
\hline \multicolumn{3}{|c|}{$G a N / A l_{0.15} G a_{0.85} N / A l N$} & \multicolumn{3}{|c|}{$I n_{0.16} G a_{0.84} N / I n_{0.04} G a_{0.96} N / G a N$} \\
\hline 6 & 0.314 & 40 & 6 & 0.179 & 28 \\
\hline 12 & 0.226 & 38 & 12 & 0.091 & 28 \\
\hline
\end{tabular}



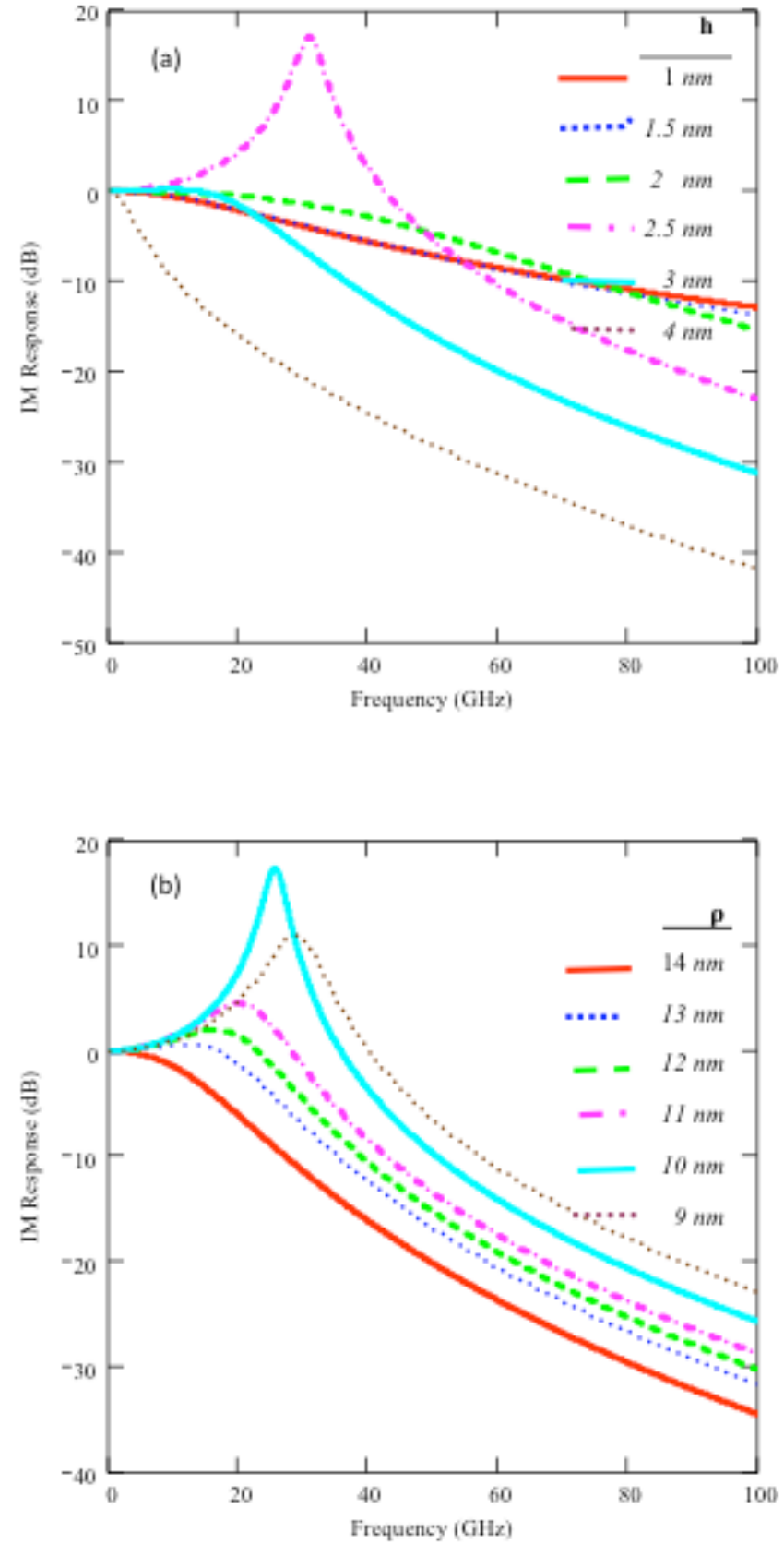

Fig. (10). IM response at various indicated sizes for (a) disk radius at $\rho=14 \mathrm{~nm}$ and (b) disk height at $\mathrm{h}=2 \mathrm{~nm}$ for $\mathrm{GaN} / \mathrm{Al}_{0.25} \mathrm{Ga}_{0.75} \mathrm{~N} / \mathrm{AlN}$ QD structure. Calculations are done at (6 acc/QD).

effects on IM response are shown in Figs. (10a and 10b) for $\mathrm{GaN} / \mathrm{Al}_{0.25} \mathrm{Ga}_{0.75} \mathrm{~N} / \mathrm{AlN}$. As seen from Fig. (10a), the bandwidth $(B W)$ increases with height until $h=2.5 \mathrm{~nm}$ then damping increases, while it increases with longer radius as in Fig. (10b). A similar behavior is seen for InGaN structure (not seen here). Fig. (11a) shows the dependence of the IM response on the capture time from WL to excited state $\left(\tau_{c, s c h}\right)$. It shows that it increases $B W$ and $f_{R}$ then, they are reduced for longer $\tau_{c, s c h}$ times $(3 n s)$. Fig. (11b)
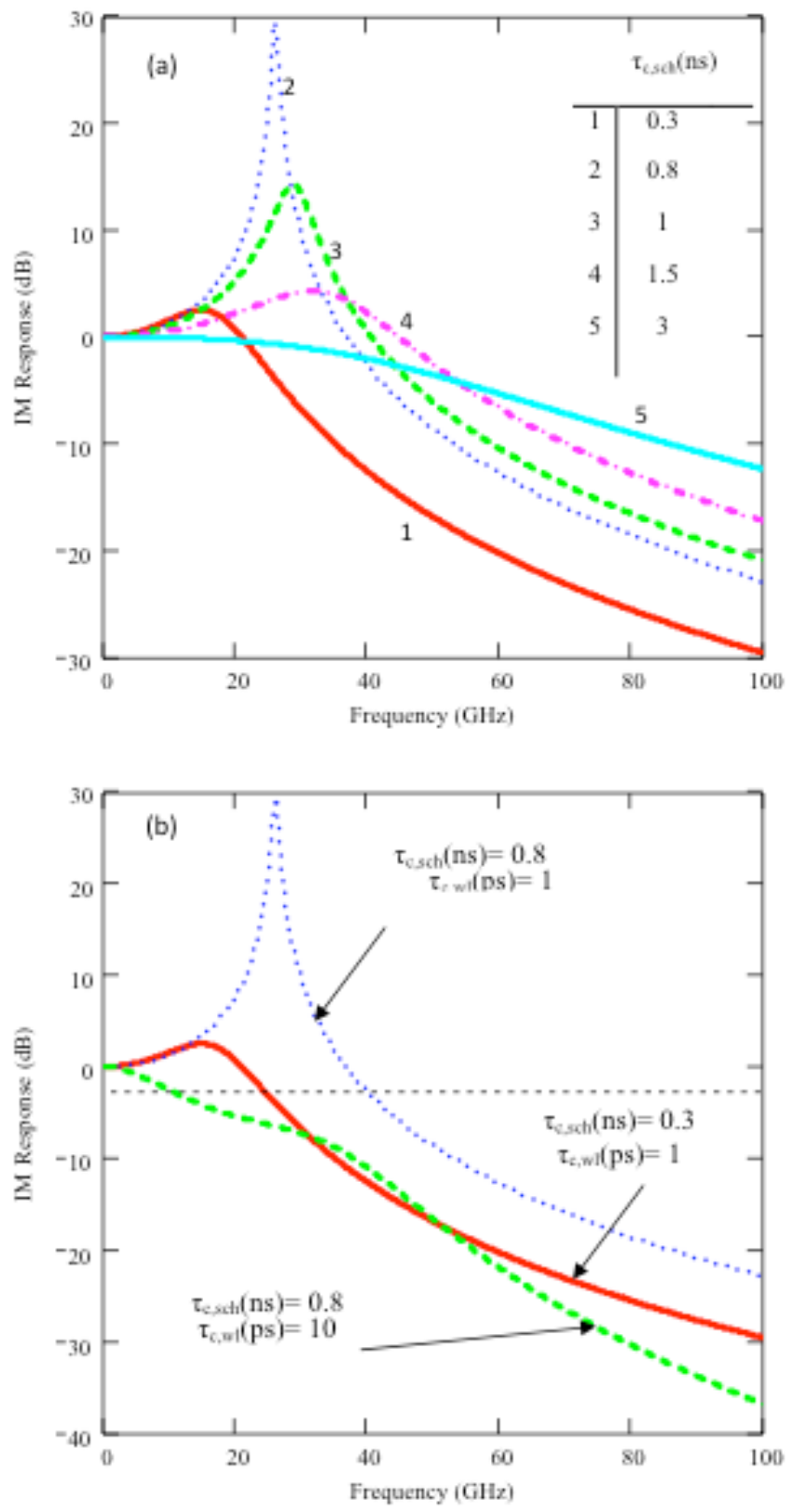

Fig. (11). (a) Dependence of the intensity modulation response on $\tau_{c, s c H}$ of $\mathrm{GaN} / \mathrm{Al}_{0.2} \mathrm{Ga}_{0.8} \mathrm{~N} / \mathrm{AlN}$ QD laser. (b) Intensity modulation response for different $f_{R}$ and $\tau_{c, w l}$. Both plots with $1.5 \mathrm{~mW}$ output power.

examine the same dependence in (a) for various values of capture time $\tau_{c, w l}$. Both plots taken at output power $P_{\text {out }}=1.5 \mathrm{~mW}$. Fig. (11b) shows the importance of $\tau_{c, w l}$ where a longer capture time of WL shown to give $B W$ smaller than $f_{R}$ where a premature roll off in the IM response is shown. In Fig. (12) we plot the IM response at different levels of p-doping for (a) GaN/Al $1_{0.15} \mathrm{Ga}_{0.85} \mathrm{~N} / \mathrm{AlN}$ and (b) $\mathrm{In}_{0.16} \mathrm{Ga}_{0.84} \mathrm{~N} / \mathrm{In}_{0.04} \mathrm{Ga}_{0.96} \mathrm{~N} / \mathrm{GaN}$ QD lasers, respectively. It is shown that the bandwidth increases with doping. But, after 
Table 4. Summary of Small Signal Modulation Devices Performance

\begin{tabular}{|c|c|c|}
\hline $\begin{array}{c}\text { Doping } \\
\text { (Acc/QD) }\end{array}$ & \multicolumn{2}{|c|}{$B W(\mathbf{G H z})$} \\
\hline 6 & 42.9 & 36.8 \\
\hline 12 & 43.7 & 39.2 \\
\hline
\end{tabular}
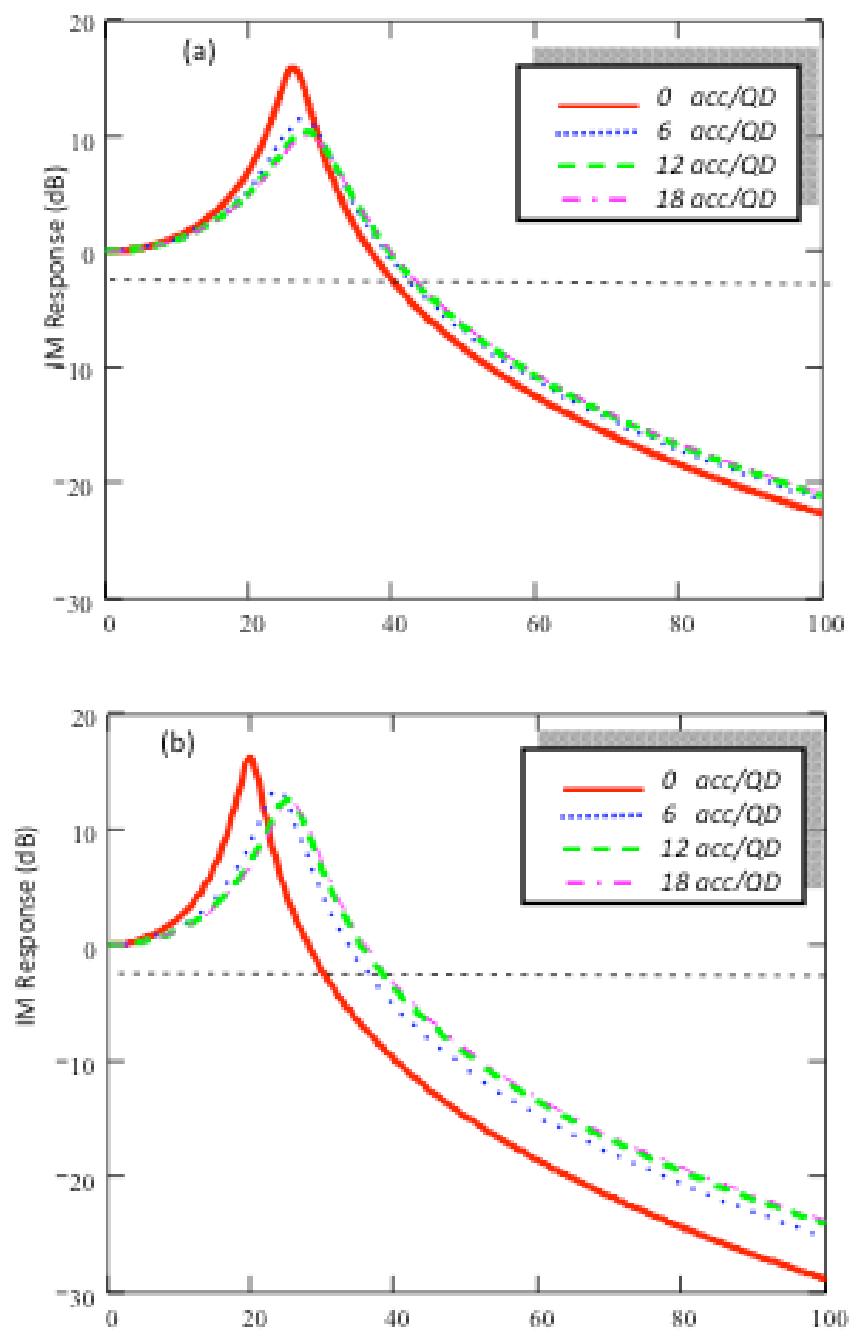

Fig. (12). Dependence of the intensity modulation response on pdoping effect of (a) $\mathrm{GaN} / \mathrm{Al}_{0.15} \mathrm{Ga}_{0.85} \mathrm{~N} / \mathrm{AlN}$ QD laser and (b) $\mathrm{In}_{0.16} \mathrm{Ga}_{0.84} \mathrm{~N} / \mathrm{In}_{0.04} \mathrm{Ga}_{0.96} \mathrm{~N} / \mathrm{GaN}$ QD laser.

(12 acc/QD) the increment is not of considerable importance. So it is important to make doping until this level, in applications require high speed, when these structures are used. Table 4 summarizes bandwidth characteristics for these stuctures. Where the bandwidth increase from 40 to $44 \mathrm{GHz}$ for GaN QDs and from 30 to $39 \mathrm{GHz}$ for InGaN QDs. While Ledentsov et al. [4] measured $59 \mathrm{GHz}$ bandwidth for GaAs QD laser emitting at 960nm, Kuntz et al. [15] measured
$1.8 \mathrm{GHz}$ bandwidth increament for InGaAs QD laser emitting at $1.3 \mu \mathrm{m}$ with $5 \times 10^{17} \mathrm{~cm}^{-3} \mathrm{p}$-doping which is the same range of increment in our structures.

\section{CONCLUSIONS}

This work studies the performance of III-N QD lasers. Two types of structures are studied: $\mathrm{GaN} / \mathrm{Al}_{\mathrm{x}} \mathrm{Ga}_{1-\mathrm{x}} \mathrm{N} / \mathrm{AlN}$ and $\mathrm{In}_{\mathrm{x}} \mathrm{Ga}_{1-\mathrm{x}} \mathrm{N} / \mathrm{In}_{0.04} \mathrm{Ga}_{0.96} \mathrm{~N} / \mathrm{GaN}$. Gain is studied for these structures where GaN QDs shown to be stands against inhomogeneous broadening than InGaN QDs. Modal gain shown to be higher for InGaN due to higher confinement. Threshold current shown to be reduced with doping while the intensity modulation bandwidth shown to increase with it. For both threshold current and bandwidth it is shown that doping is active until some value then the increment is not so important. The study covers (300-600 nm) wavelength ranges.

\section{REFERENCES}

[1] Chuang, S.L. Optical properties of strained wurtzite GaN quantumwell lasers. IEEE J. Quantum Electron., 1996, 32, 1791.

[2] Schulz, S.; Czycholl, G.; Schumacher, S. Spin-orbit coupling and crystal-field splitting in the electronic and optical properties of nitride quantum dots with a wurtzite crystal structure. arXiv:0802.2436v1 [cond-mat.mtrl-sci], 2008.

[3] Suihkonen, S. Ph.D. Thesis, Helsinki University of Technology, Fabrication of InGaN quantum wells for LED applications, 2008. http://lib.tkk.fi/Diss/2008/ISBN 9789512292875,

[4] Ledentsov, N. N.; Hopfer, F.; Bimberg, D. High-speed quantumdot vertical cavity surface emitting lasers. Proc. IEEE, 2007, 95, 1741 .

[5] Steiner, T. Semiconductor nanostructures for optoelectronic applications. Artech House Inc: Norwood, USA, 2004.

[6] Bartel, T.; Dworzak, M.; Hoffmann, M.; Strittmatter, A.; Bimberg, D. Recombination dynamics of localized excitons in InGaN quantum dots. Appl. Phys. Lett., 2004, 85, 1946.

[7] Kim, J.; Chuang, S. L. Theoretical and experimental study of optical gain, refractive index change, and linewidth enhancement factor of p-doped quantum-dot lasers. IEEE J. Quantum Electron., 2006, 42,942 .

[8] Kerstnikov, I. L.; Strassburg, M.; Strittmatter A.; Ledentsov, N.N.; Christen, J.; Hoffmann, A.; Bimberg, D. Direct evidence of nanoscale carrier localization in $\mathrm{InGaN} / \mathrm{GaN}$ structures grown on $\mathrm{Si}$ substrates. Jpn. J. Appl. Phys., 2003, 42, L1057.

[9] Park, S. H.; Ahn, D.; Chuang, S. L. Electronic and optical properties of a- and m- plane wurtzite InGaN-GaN quantum wells. IEEE J. Quantum Electron., 2007, 43, 1175.

[10] Fiore, A.; Markus, A. Differential gain and gain compression in quantum-dot lasers. IEEE J. Quantum Electron., 2007, 43, 287.

[11] Gioannini, M.; Montrosset, I. Numerical analysis of the frequency chirp in quantum-dot semiconductor lasers. IEEE J. Quantum Electron., 2007, 43, 941.

[12] Coldren, L.A.; Corzine, S.W. Diode lasers and photonic integrated circuits. John Wiley \& Sons: New York, USA, 1995. 
[13] Al-Khursan, A.H. Intensity noise characteristics in quantum-dot lasers: four-level rate equations analysis. J. Lumin., 2005, 113, 129.

[14] Fischer, M.; Bispan, D.; Marquardt, B.; Forchel, A. Hightemperature continous-wave operation of GaInAsN-GaAs quantum-dot laser diodes beyond $1.3 \mu \mathrm{m}$. IEEE Photon. Technol. Lett., 2007, 19, 1030 .
[15] Kuntz, M.; Fiol, G.; Iammlin, M.; Bimberg, D.; Thompson, M.; Tan, K.; Marinelli, C.; Wonfor, A.; Sellin, R.; Penty, R.; White, I.; Ustinov, V.; Zhokov, A.; Shernyakov, Y.; Kovsh, A.; Ledentsov, N.N.; Schubert, C.; Marembert, V. Direct modulation and modelocking of $1.3 \mu \mathrm{m}$ quantum dot lasers. New J. Phys., 2004, 6, 181.

(C) Al-Husseini et al.; Licensee Bentham Open.

This is an open access article licensed under the terms of the Creative Commons Attribution Non-Commercial License (http://creativecommons.org/licenses/by-nc/3.0/) which permits unrestricted, non-commercial use, distribution and reproduction in any medium, provided the work is properly cited. 